\title{
Beyond Plants, Professionals \& Parchments: The role of home-based medicinal plant use and traditional health knowledge in primary health care in Ethiopia
}

\author{
Hareya Fassil
}

\begin{abstract}
This paper is concerned with the use of medicinal plants and the related lay traditional health knowledge and practices among rural communities in the Bahir Dar Zuria Wereda (district) of Gojam located in the northwestern highlands of Ethiopia.
\end{abstract}

Much of the research on Ethiopian traditional medicine and medicinal plants to date has been carried out in a compartmentalized manner, with researchers from various disciplines pursuing their interests in the subject in relative isolation. Most studies have been driven by a specific interest in the properties of particular medicinal plants, focusing on two main sources of information, i.e., the knowledge of professional traditional health practitioners and the ancient medico-religious herbal manuscripts with which, the religious traditional health practitioners or debterra, in particular, are closely associated. Focus on the professional realm of traditional health has detracted attention from others in the community who may also be knowledgeable about plant-derived treatments and cultural health practices. Due to the resulting overall 'plantfocus', relatively little attention has been paid to the local socio-cultural context in which many medicinal plants continue to be used by ordinary local people and knowledge about them developed and passed on over generations. The preliminary findings of a study seeking to address this research gap by focusing on lay community members are presented here. Qualitative and quantitative analysis of the data gathered through the main phase of the field research (carried out over the period August-December, 2000 ) is still underway. Nevertheless, this presentation offers an opportunity to discuss some of the general trends and preliminary findings of the household surveys and interviews held with members of five rural farming communities in Bahir Dar Zuria and to revisit the central hypothesis and objectives of the research in light of these findings.

\section{Introduction}

At this very moment, somewhere in the rural hinterland of the Ethiopian Highlands, a local farmer may have just gathered leaves or root parts from a local medicinal plant found near the homestead. In a nearby village, a mother might be in the midst of preparing a traditional plant treatment believed to 'restore strength', relieve stomach cramps, heal a skin condition, 'ward off the evil-eye' or perhaps to help alleviate symptoms of a respiratory tract infection. It is such routine use of local medicinal plants by ordinary members of local communities across the country's diverse and largely rural landscape which accounts for the widely cited $80 \%$ estimate of the population who continue to use traditional plant-derived medicines for their primary health care needs $(\mathrm{MOH} 1985$, Abebe \& Hagos 1991, Abebe \& Ayehu 1993, IBCR1999).

As in many African countries, this continued reliance on traditional medicines is partly due to economic circumstances, which place modern health facilities, services

\section{Correspondence}

Hareya Fassil, Green College, University of Oxford, Woodstock Road, Oxford, England OX2 6HB, UNITED KINGDOM.

hareyafassil@yahoo.com

Ethnobotany Research \& Applications 3:037-049 (2005) 
and pharmaceuticals out of the reach of the majority of the population. However, in many cases, it is also attributable to the widespread belief in the effectiveness of many traditional therapies. Even where Western biomedical care is available, many people still prefer traditional treatments for treating many conditions, suggesting that the latter will continue to play a major role in national health care into the future (Sindiga 1995, van der Geest 1997). Indeed, there is growing recognition that revitalization and promotion of traditional health practices alongside modern health services is the most promising means for ensuring affordable and sustainable health care for poor communities throughout Africa (Akerele1987, Anokbonggo 1992, Cunningham 1993).

Despite growing recognition of traditional health practices as an essentially multidisciplinary research topic, botanists, natural chemists, pharmacologists, anthropologists and health-workers have, to date, generally pursued their specific research interests in this area in relative isolation from each other. In the case of Ethiopia, there have been few cross-disciplinary linkages among the various approaches of researchers or the analysis of their findings to date. Moreover, in search of information on the properties of various Ethiopian medicinal plants researchers have targeted much of their efforts on:

- ' the professionals': specialized knowledge and practices believed to be restricted to professional traditional health practitioners; and

- 'the parchments': Ethiopian medico-religious manuscripts, dating back as far as the 15th century (Abebe \& Ayehu 1993) containing elaborate herbal recipes for various conditions.

As a result, there have been few studies of Ethiopian traditional medicine concerned with the current local contexts in which the plants and health practices continue to be used by local people. Fewer still, have focused specifically on the knowledge and practices of those outside the professional realm of traditional medicine. The study presented here was envisaged as a contribution to bridging this research gap.

\section{Background}

\section{Ethiopia's ecological and cultural diversity}

Ethiopia's varied topographical and climatic conditions have shaped a set of macro- and micro-ecosystems with a rich biological diversity. The flora of Ethiopia consists of some $6,000-7,000$ species, about $10 \%$ of which are believed to be endemic to the country. Medicinal plants occur throughout the country's diverse highland areas as well as in south-west and central lowlands (FAO 1996).

Ethiopia is also one of the most culturally diverse countries in Africa. More than 80 distinct languages are spoken in the country (Grimes 1996). About two-thirds of Ethiopians speak Amharic, Oromigna or Tigrigna. In addition, a large diversity of smaller ethnic groups, mostly pastoralists and agriculturalists, inhabit isolated areas, mainly in the western and southern lowlands. Even within relatively restricted geographic areas, there is often a great diversity of ecological conditions, farming practices and production systems, upon which the livelihoods of Ethiopia's diverse peoples depend (Kiros 1993). The country's rich biodiversity also extends to a wide range of diseasecausing agents. Over many centuries, local communities throughout Ethiopia have attempted to combat these diseases through a range of religious and secular traditional practices many of which are based on herbal treatments (Abebe \& Ayehu 1993, Bishaw 1991b).

\section{Focus on the professionals}

The main research strategies pursued to date would suggest that traditional health knowledge is a 'specialized' body of knowledge restricted to professional traditional healers. This assumption would imply that most of the estimated $80 \%$ of Ethiopians depending on traditional medicine invariably consult professional traditional healers for most health problems. To what extent is this true? This study set out to investigate this question.

As in many other countries, traditional healers in Ethiopia are generally highly regarded for their valuable knowledge regarding the therapeutic properties of plants (Abebe \& Ayehu 1993, Bishaw 1991b, Young 1976, 1982). It is not surprising therefore, that the knowledge and practices of traditional health professionals have constituted an important subject of research on Ethiopian traditional medicine.

The main types of Ethiopian traditional health practitioners have been summarized by several researchers (Bishaw 1991b, Kaba 1993, Kenaw 1997, Slikkerveer 1990, Young 1982). Among the Amhara, there is a great deal of interplay between mystical and empirical concepts of disease and treatment both among secular and spiritual healers (Young 1976, 1982). Much of the research attention has, to date, focused primarily on the knowledge and practices of the spiritual debterra - learned clergy men (in this case, always men!) with an Ethiopian Orthodox church education. The secular "medhanit awaki" (lit. "one who knows medicine") have also received considerable research attention (Bishaw 1991b).

However, it is only recently that researchers have succeeded in involving the debterra in the documentation of traditional medicinal plants and their various uses (Abebe \& Ayehu 1993, Tadesse \& Demissew 1992). The debterra have tended to be secretive about their knowledge, often claiming that disclosing information on the use of plants would compromise the efficacy of the remedies (Abebe \& Ayehu 1993). The extent to which these claims are 
grounded in genuine cultural belief rather than pragmatic socio-economic interests, i.e. as a means for protecting their livelihoods, remains open to speculation. However, traditional healers have been known to sometimes deliberately provide incomplete or misleading information on the preparation and use of various herbal treatments (Abebe \& Ayehu 1993). Hence, the reliability of the information provided and, more importantly, how it relates to current health practices in the public domain, has not always been clear.

\section{Focus on the 'parchments'}

Most African health traditions, including those in Ethiopia, are passed down over generations by word of mouth. However, Ethiopia also has an ancient written health tradition, which has been the focus of many studies to date. This focus has overlooked the diversity of the country's oral health doctrines and the associated local knowledge regarding medicinal plants.

Monasteries throughout the northern Highlands have long served as the custodians of ancient codified medico-religious manuscripts known as Etse-Debdabe (herbal letters), containing recipes for herbal treatments for a range of health conditions. Very few of the church educated debterra who read and write both Amharic and Ge'ez (the ancient church language in which these manuscripts are written) have cooperated with researchers in deciphering these ancient texts. A few prominent debterras such as Gelahun Abate (Abate et al. 1976) and Ahadu Ayehu (Ayehu 1987) have also transcribed their specialised knowledge into voluminous compendia of herbal recipes. Most of these however, are like textbooks for apprentices or initiates into the religious culture. For example, although transcribed into modern Amharic, Ahadu Ayehu's semi-codified religious diction and specialized cultural terminology, renders his herbal recipes difficult for the lay reader to comprehend without the guidance of specialists. The same is generally true of other such herbal letters (Berhane-Selassie 1971). Another major effort is the decodification and translation into English of 15th century Ethiopian medico-religious manuscripts (Abebe \& Ayehu 1993).

Interest in these ancient herbal letters has skewed the research focus to the Ethiopian churches and monasteries, where the manuscripts are believed to have originated, and where knowledge about them still exists among the local debterras. Yet, in addition to the difficulties involved in de-codifying and interpreting the diseases described, determining the identity of the medicinal plants cited has proven difficult (Tadesse \& Demissew 1992). What is conspicuously absent from these texts is the 'context', i.e. how these records relate to current local realities. Although it is postulated that many of the traditional practices of different cultural groups throughout the country are related to these written pharmacopoeia (Bishaw 1988, 1991a), there has been no systematic effort, to assess the extent to which this ancient literature reflects current local traditional health practices at the local level.

\section{Focus on the plants}

Approximately 600 native Ethiopian plant species are known to have medicinal value (AgroBioEthiopia 1996). Given the overall diversity of Ethiopia's vegetation, comprising some 6500-7000 flowering species (FAO 1996, IBCR 1999), it is very likely that a much larger number of species (some perhaps not yet taxonomically identified) belong to this important category. A systematic inventory of the country's medicinal plant resources figures among the planned activities of the cross-sectoral research and development project recently approved for World Bank support (IBCR 1999).

In the meantime, however, most botanists, natural chemists, pharmacologists, and, more recently, conservationists, have concerned themselves primarily with native species considered to be 'major' or 'significant' for a variety of reasons. Although the criteria used for prioritizing plants for research are not always self-evident in the literature, the following are some of the largely pragmatic considerations that can be discerned:

- $\quad$ plants most widely distributed throughout the country or those dominant in a particular community or region [e.g.,(Abebe 1986, Desta 1993) ];

- those widely traded/in high demand, commonly found in herbal markets [e.g., (Kloos 1976, Kloos et al. 1978, Jansen 1981)];

- $\quad$ plants associated with adverse side-effects/ toxicity [e.g.,(Low et al. 1985)];

- $\quad$ plants frequently cited in the prescriptions of traditional healers, [e.g.(Abebe 1986) or ancient herbal letters [e.g.,( Abebe \& Ayehu 1993)].

In most cases, a combination of such criteria have directed the focus of various investigations, largely on the specific therapeutic properties of individual plants. The question remains, however, as to how to link this systematic taxonomic classification of plants and the findings of extensive laboratory assays with the current uses of these plants in traditional medicine. To be useful, such scientific findings need to be linked with the specific uses of plants not only within the professional realm of traditional medicine, but also to their various applications by lay community members at the local level. It appears however, that the underlying assumption of the research agenda to date has been that the uses of these plants drawn from herbal texts or provided by professional traditional herbalists reflects the actual uses of these species in the local communities where they occur.

There has thus, been an overall 'plant focus', which has meant that much of the work carried out thus far, has ultimately been driven by an interest in particular medici- 
nal plants and their specific constituents. Relatively little attention has been paid to the broader and dynamic socio-cultural context in which medicinal plants continue to be employed by ordinary people in local communities and knowledge about them developed and passed on. Hence, the approach of this study: to explicitly focus on the knowledge and practices of lay community members in contemporary rural Ethiopia.

\section{Conceptual Framework}

\section{Theoretical foundations}

The overall aim of the research presented here is to contribute to the growing body of literature on the role of indigenous or traditional systems of knowledge in development. It seeks to do this by improving understanding of the local management and use of medicinal plants and the associated local traditional knowledge. The underlying premise is that health constitutes the linchpin of the development process. It can at once be viewed both as the means as well as the end of development.

Within such a context, this study aimed to gain insight into the distribution of traditional health knowledge at the local level and how it is maintained and transmitted over generations in rural communities in the Ethiopian Highlands. Set out below is the central hypothesis of the study, which is envisaged as a counter thesis to the question posed at the beginning of the previous section.

\section{Central hypothesis}

Significant local knowledge regarding the management and use of medicinal plants as sources of home-based medicines is held by ordinary Ethiopian men and women. Women and elders are often among the main custodians of such traditional health knowledge. Women in particular play special roles in traditional health care delivery both in their capacities as mothers and as principal managers of plants grown in home-gardens.

\section{Study Area and Participating Communities}

The area where this study was conducted is known as Bahir Dar Zuria wereda (district) in a region known as Gojam located in the heart of the Ethiopian Highlands (Figure 1A). The people in this area, known as the Gojamie, are members of the Amhara ethnic group and are largely adherents of Ethiopian Orthodox Christianity. The Gojamie, including all the study communities speak Amharic, which is also the most widely spoken official national language of communication.

With a population of 25,745 (CSA 1998), the district, comprises a total of 36 rural kebelies or peasant associations (hereafter, referred to as 'farming communities'). Five of these rural farming communities (one from each of the total five sub-districts) were included in the study: Robit Bata; Yinesa Sostu; Yigoma Huletu; Wend Atta and Yiganda Mehal Zegie. Each of the communities lies within a $15-20 \mathrm{~km}$ radius of the Bahir Dar town, thus forming a roughly even distribution around the urban centre as shown in Figure 1B. With the exception of Yiganda Mehal Zegie, where the livelihood of local people depends primarily on the production and marketing of coffee, subsistence agriculture constitutes the livelihoods of the participating communities. The main crops cultivated include teff (Eragrostis tef (Zucc.) Trotter), dagussa (Eleusine coracana (L.) Gaertner), nug (Guizotia abyssinica (L.f.) Cass.) and maize as well as a range of legumes and vegetables.

\section{A Multidisciplinary Methodological Framework}

The study of traditional health care systems is a multifaceted endeavor necessitating a multidisciplinary and participatory research framework. In recognition of this, a combination of research tools from various disciplines were employed in this study. Gender considerations constituted an integral aspect of the study as important gender factors were expected to be involved in the type, extent and inter-generational transmission of traditional knowledge, in the management and use of herbal medicines and in the delivery of traditional health services. Guidelines for integrating gender considerations into biodiversity research (IDRC 1998) were consulted throughout the study.

There was considerable overlap in terms of the information elicited by these tools from different groups of informants. This inter-connectedness was envisaged as a means of cross-checking data gathered from various sources, in different settings (households, herbal markets, schools, traditional health care centres, government health-posts clinics/hospitals), and through different means. The seven main components of the methodology are outlined below.

\section{Household surveys}

The household surveys, which essentially constitute the main component of the field work, involved semi-structured interviews with both women and men household heads. As the aim was to gain insight into the knowledge and practices of lay community members, random samples of households stratified by gender were drawn in each community. In the first four communities (R.Bata, Y.Sostu, Y.Huletu, Wend Atta), about 30 household heads each were randomly sampled; a further 42 household heads were included from the last community Yiganda Mehal Zegie, resulting in data from over 160 men and women informants in total. 


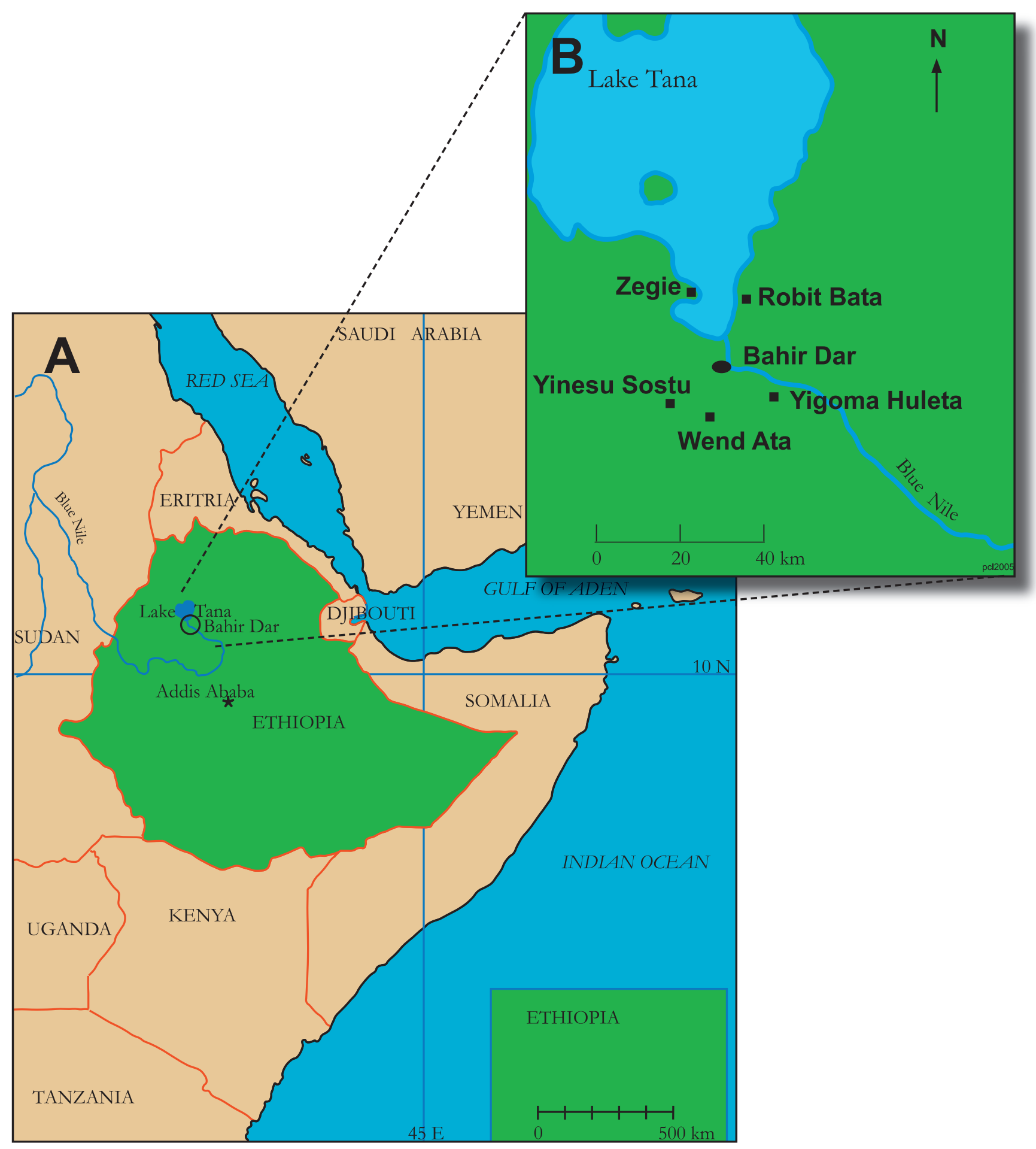

Figure 1. A. Ethiopia with research area in Bahir-Dar Zuria Wereda in the Ethiopian Highlands. B. Five participating rural communities in the area of Bahir-Dar Zuria Wereda. All are 15-18 km from the regional center. 
The interview schedule employed by the survey included detailed open-ended as well as closed questions. These ranged from specific questions regarding traditional plant treatments known or routinely used for a list of common health problems, to more general ones about access to and use of government biomedical health services and perspectives regarding 'modern' vs. traditional approaches to health as a whole.

\section{Oral histories}

Open interviews were held with widely recognized knowledgeable elder members in each research community. The aim of this was to gain insight into:

- the overall historical perspective of the culture and traditions of each community, including an understanding of traditional gender roles and relations;

- the overall state of the local natural environment, the extent of habitat conversion and changing land use patterns over the years, including any losses of locally valued plants;

- local perspectives regarding major health problems/ diseases in the area over the years; and

- changing perspectives regarding the advantages and drawbacks of traditional medical practices vs. modern medicine.

The outcome of these discussions proved very useful for refining the questions asked in the other methodological components.

\section{Focused discussions mothers at local health posts}

Regular child immunization programmes held at local government health centres provided an opportunity to focus on the traditional health knowledge and practices of women. Focus group discussions had originally been planned as the method to be used for this research component. However, group discussions proved impractical for at least two reasons. First, women were often pressed for time and were primarily concerned about getting their child vaccinated as soon as possible in order to tend to their other duties. Secondly, rural women from this area are generally not accustomed to voicing their opinions and concerns in public. An alternative was therefore, devised wherein individual interviews were held with interested volunteers. The discussions included a special focus on traditional knowledge, practices and herbal medicines pertaining to maternal and childcare.

\section{Survey of herbal markets}

Informal discussions with herbal vendors were envisaged as a means of investigating the knowledge of herbal vendors in local markets -- another important group of people who were deemed likely to hold special knowledge regarding the uses of medicinal plants.
To date, studies on herbal markets in Ethiopia (Jansen 1981, Kloos 1976, Kloos et al. 1978) have focused on the plant medicines for sale, rather than the role and knowledge of the sellers. However, such studies do inadvertently provide insights into the strategic locus occupied by herbal vendors. Although they rarely have any formal training, they may possess knowledge regarding the preparation and administration of different plant medicines for home use (Marshall 1998). Their intermediary role also may afford them knowledge about both the sources and the extant demand for various plants.

Contrary to expectations, however, there were virtually no local 'herbal markets' per se in the rural communities studied. Hence, not enough information could be gathered to enable a meaningful assessment of the overall role of herbal market vendors and the particular type of knowledge they might possess. However, four general local markets were visited: Zenzelima, Meshenti, Bahir Dar central market and the Affaf market on the Zegie peninsula. The few herbal vendors encountered were all Muslim women, primarily selling food spices and plant products for cosmetic use including a range of plant parts used as incense or fumigants.

\section{Written questionnaires administered to high-school students}

In collaboration with a Biology teacher at the Tana Haik Secondary School, in Bahir Dar town, questionnaires were administered to 35 student volunteers (20 male and 15 female students, age 18-22 years from both rural and urban backgrounds). The aim was to gain insight into the extent and mechanisms through which traditional knowledge regarding the use of various medicinal plants is transferred to the young.

Questions similar to those in the household survey were included. The data obtained will be disaggregated by gender and family background (including a comparison of the traditional knowledge reported by students brought up in rural areas to those who come from the urban centre) to see whether such factors account for any significant differences in traditional health knowledge based on the use of medicinal plants.

\section{Structured interviews of professional health practitioners}

During the household survey, informants were asked about their use of modern health care services. In a number of cases, informants specifically cited the modern health care providers (mostly located in central Bahir Dar town) from whom they frequently seek care for specific health problems. Formal interviews were conducted with modern health practitioners at three of the most frequently cited medical facilities: Gambi Clinic (private); Tikur Abbay clinic (private) as well as Bahir Dar Health Station - the largest out-patient government health care facility in the area. Topics covered by the interviews included the following: 
- information on the facilities/ equipment, trained personnel and services provided;

- types of patients treated; major diseases/ health problems;

- $\quad$ perspectives regarding the role of home-based traditional medicine/use of medicinal plants; and

- $\quad$ biomedical interpretations of traditional terms for various health conditions.

Likewise, three well-known traditional healers based in B/ Dar town (recommended by the Head of the Traditional Healers Association in Eastern Gojjam zone) were also interviewed. Discussions with these traditional healers covered the following:

- background/training and area of expertise (main diseases treated);

- $\quad$ perspectives/attitudes regarding biomedicine, including relevant referral practices;

- major sources and current situation regarding medicinal plant supplies;

- $\quad$ perspectives regarding major illnesses in area and the role of home-based traditional medicine/use of medicinal plants by lay persons.

Collation of background information from secondary sources: National heath statistics reports, local government documents and relevant project findings of development agencies in the region were gathered to provide background socio-cultural information, including data on population and demographics; health indices and available government health facilities and services, as well as general information on the local ecology and natural resources.

\section{Preliminary Assessment of Data}

\section{General observations}

"Why, even a goat would know which medicinal plant to nibble on when bitten by a snake!"

[Translation of a remark made by a member of the Yinesa Sostu community]

Tacit and pervasive nature of traditional health knowledge

In general, traditional knowledge about local medicinal plants and traditional medicines is very much taken for granted by both men and women members of the local communities studied, as shown by the above quote. The questions asked were typically met with surprise by most informants, who were often initially puzzled as to why the subject matter would be of any interest to others.

\section{Consistency of plant-specific information}

On the whole, the information obtained from different informants was consistent. The consistency of plant-specific information in particular, is best illustrated by the case of a plant locally known as inqoqo (Embelia schimperi). Almost all of those who cited this plant in all five communities gave similar assessments regarding its primary habitat, its application, preparation, appropriate dosage, efficacy relative to other traditional treatments, as well as the reasons behind why its popularity has declined of the years. The various local names of most medicinal plants cited were also consistent in most cases.

\section{Gender and age differences}

Some general trends could also be discerned suggesting considerable gender and age differences in the type and extent of traditional health knowledge pertaining to the uses of various medicinal plants. In general, middle-aged women and men (approx. 40-60 years old) seem to have a greater breadth of knowledge, encompassing plant location (knowledge of primary habitats), identification, collecting, preparation and administration of the treatments. Further, women were frequently able to provide more details regarding preparation of treatments. Another general trend was that men were often more knowledgeable than women about traditional plant treatments for various ailments in cattle. In general, men also demonstrated more knowledge of plants that are primarily procured from the wild and nearby forests, whereas women generally showed greater familiarity with the medicinal uses of wild/weedy and cultivated plants found around the homestead.

\section{Main sources of traditional knowledge}

During the household surveys, informants were asked to identify 'the main source' of their knowledge. The top five sources cited are outlined in Table 1. 'Routine observation and practice' ('learning by doing') was the most widely cited (37.3\% of all informants) route through which knowledge is acquired. The second largest group (21.6\%) identified their father as the main source of their knowledge,

Table 1. Top five main sources of traditional knowledge cited by men and women participants of the household survey (Total sample: 164 informants)

\begin{tabular}{|l|l|l|l|l|l|}
\hline $\begin{array}{l}\text { \% of informants } \\
\text { by gender }\end{array}$ & $\begin{array}{l}\text { Routine observation and } \\
\text { practice ('learning by doing') }\end{array}$ & $\begin{array}{l}\text { Father } \\
\text { (only) }\end{array}$ & $\begin{array}{l}\text { Mother } \\
\text { (only) }\end{array}$ & $\begin{array}{l}\text { Both } \\
\text { parents }\end{array}$ & $\begin{array}{l}\text { Other acquaintances/ } \\
\text { knowledgeable persons }\end{array}$ \\
\hline Men & $41.5 \%$ & $23.7 \%$ & $14.4 \%$ & $5.9 \%$ & $7.6 \%$ \\
\hline Women & $22.9 \%$ & $14.3 \%$ & $31.4 \%$ & $20 \%$ & $2.9 \%$ \\
\hline Total & $37.3 \%$ & $21.6 \%$ & $18.3 \%$ & $9.2 \%$ & $6.5 \%$ \\
\hline
\end{tabular}


with more men than women responding in this way $(23.7 \%$ of men, $14.4 \%$ of women). While the largest proportion of men indicated that routine observation and practice was the main means by which they acquired their traditional health knowledge and skills, most women cited their mothers as their main 'source' of knowledge.

Characteristics and use patterns of local medicinal plants The local names and specific use of more than 100 plants were documented throughout the study. This finding in itself is strongly supportive of the first component of the research hypothesis, i.e. that significant knowledge about medicinal plant use exists in the 'non-professional'/ public domain. Very few of the plants cited are trees; most are wild and weedy species, which occur naturally around the homestead or farm, often requiring little management. Relatively few of the species cited are cultivated. It should also be noted that medicinal plant use by the local communities is largely of a home-based 'subsistence' nature, i.e. no large-scale harvesting or trade of medicinal species was observed or reported in any of the study communities. In addition, it appears that home-gardening is not a universal activity among the study a communities. Although often, some naturally occurring weedy medicinal species are deliberately maintained around the homestead and some culinary herbs with medicinal value are also cultivated in backyards, home-gardens generally seem to play a much less pronounced role in the local culture than perhaps in other regions of the country (see for example, Asfaw 1998).

\section{Role of professional health practitioners}

On the whole, professional traditional healers also seem to have a much less pronounced role than was expected. Very few informants reported consulting professional traditional healers. Where consulted, rural traditional healers are often sought for their specialized knowledge mainly for the following health problems:

- $\quad$ ailments believed to be inflicted by the evil eye: traditional healers who provide yebuda medhanit

- Ye wisha beshita (the biomedical equivalent of which is rabies)

- Yewef beshita (the biomedical equivalent of which is hepatitis $B$ ).

(Often, rural traditional healers are believed to have knowledge of treatments for two or all three of these ailments).

\section{Puzzles, paradoxes and eye-openers}

This second part of the preliminary data assessment is the outcome of some further reflection about various features of the traditional health knowledge which this research set out to characterise. Some questions, inherent paradoxes and eye-openers encountered are discussed under three main headings: a) the potential role of traditional health knowledge: challenges \& limitations; b) the knowledge transmission process and erosion of knowledge c) contrasting features of traditional health knowledge. a) The potential role of traditional health knowledge: challenges \& limitations

Traditional knowledge vis à vis the major health problems in the area: malaria

The term 'challenge' immediately brings to mind the single largest health problem in the study area - malaria. Surprisingly, no traditional medicinal plant treatments per se for malaria were reported. While this raises a number of questions regarding how 'new' malaria is to the area it also seems compellingly related to the fact that overall understanding of malaria etiology is extremely poor among the local people. However, the remains of some relevant traditional perceptions regarding the general 'ecology' of the disease could be discerned. For example, anecdotes from some older informants indicate early association of the disease with warm and moist climatic conditions as well as the seasonal retreat of local people to the cooler and drier high altitude areas during certain months of the year in order to avoid what was perceived as the 'malaria season'. According to informants, malaria was also much less widely spread in the study area during earlier times than it is today.

Reliance on traditional medicine vis à vis dire sanitary conditions

It would seem that communities who rely heavily on plant derived traditional treatments and traditional health practices are caught in an uphill battle as most of the health problems experienced are linked to poor sanitary conditions. The lack of proper latrines, waste disposal and clean water can be viewed the raison d'être for some traditional medicines. But at the same time, these very concerns may, in fact, be among the greatest obstacles to the full realization of the potential of traditional knowledge and approaches in meeting local public health needs.

b) The knowledge transmission process: erosion of traditional knowledge?

Mythical' medicinal plants in folklore vis à vis erosion of traditional knowledge

Local folklore is another way in which oral traditions can be kept alive over generations. A very widely cited proverb (translated from Amharic below) about a plant locally known as igziwa serves as an interesting example:

"With igziwa in your front yard growing; Why is it then that your child is dying?"

While informants were often familiar with this traditional adage, they seldom knew of the specific uses of the plant to which it refers. Very few, in fact, recognized the botanical plant itself. Indeed, igziwa seems to have become somewhat of a 'mythical plant', thus begging the question whether indeed, this is a symptomatic example of traditional knowledge under threat. 


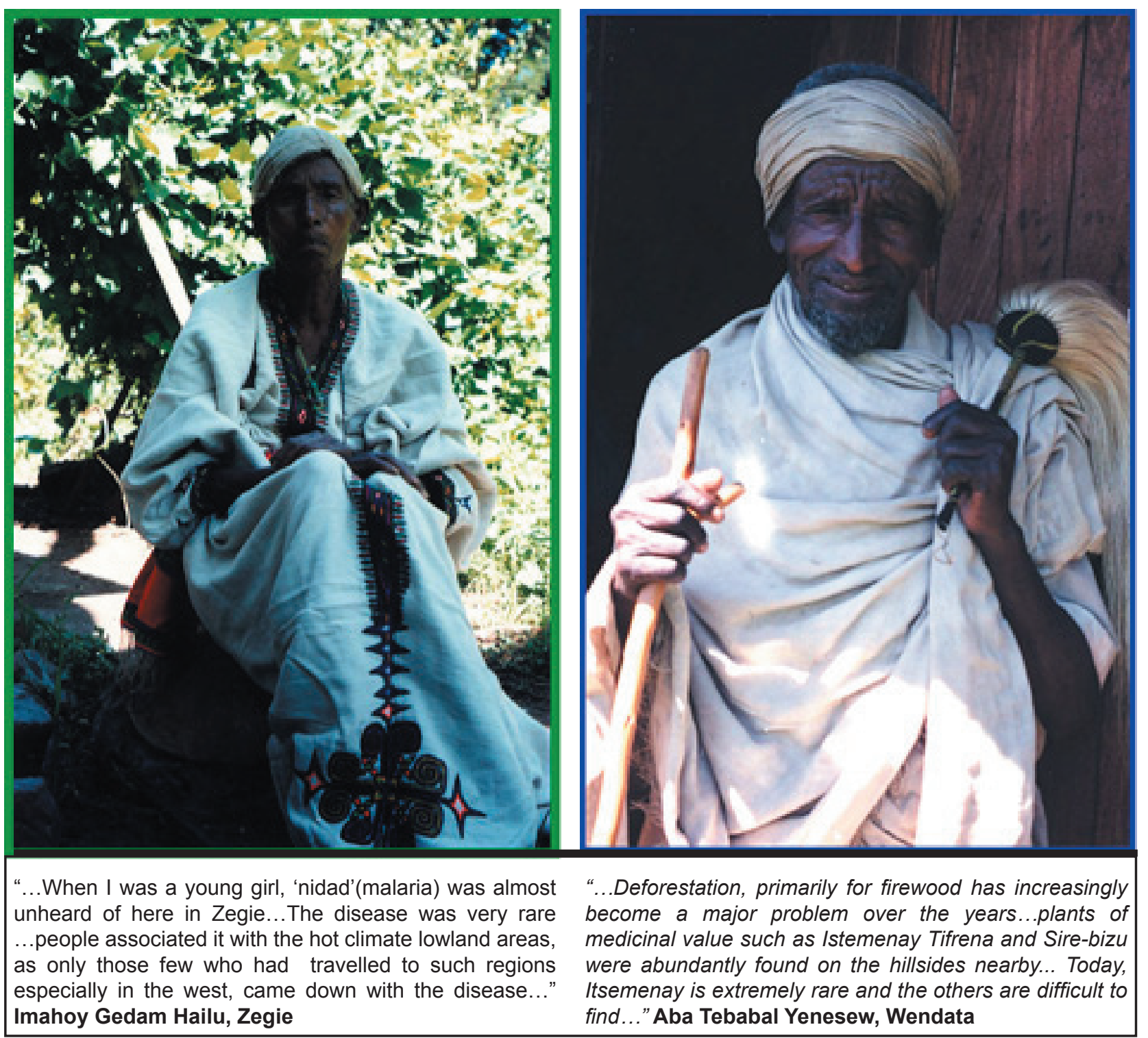

Traditional botanical knowledge among children vis à vis selective erosion of traditional knowledge

Exactly how is traditional health knowledge transmitted over generations? Are the traditional mechanisms that have been in place in the past still intact? One observation which may have some relevance to these questions concerns traditional knowledge among children. It was observed that boys and girls as young as 6-7 years old had remarkable traditional 'botanical' knowledge, i.e., the ability to distinguish various medicinal plants. They were often easily able to locate specific medicinal plants growing around the homestead. Several women informants also indicated that they would frequently have their children gather the medicinal plants they needed from areas near the homestead. It seems that this type of knowledge is maintained through observation and practice and the general familiarity of children with their 'play-ground', i.e.,

the natural environment they live in. But can one assume that this 'botanical' aspect of traditional knowledge will be safely maintained through generations simply through casual observations and 'learning by doing'? And what of other aspects of traditional health knowledge pertaining to the preparation/administration of medicines and the diagnosis of disease? Could knowledge about these aspects be 'selectively' threatened because of the particular way in which they are transmitted? These are important questions will be investigated through further analysis of the information gathered. 
c) Contrasting features of traditional health knowledge

Traditional empirical units of measurement vis à vis enigmatic procedures and practices

Ethiopian traditional health practices, like most other African health traditions, are based on a mixture of both natural and the supernatural explanations. There is a great deal of interplay between empirical concepts of disease and treatment on the one hand, and mystical explanations and practices on the other.

One of the greatest criticisms of herbal remedies used in traditional health practices has been concerned with the 'unstandardised' nature of the dosage prescribed. But this study revealed that while there may be scope for fine-tuning the methods, traditional treatments are not entirely devoid of all measurement and standards. For example, most informants demonstrated awareness of the toxicity of some plants and specific plant parts when administered in large doses. Rudimentary measurement units are routinely used to measure the plant part (usually the root-parts) as well as the amount of water used to prepare the plant treatment (e.g. in preparing an aqueous extracts from crushed leaves). The most widely cited examples include the atq, which is the length of the upper phalange (often the fore-finger; ranging roughly $2-2.5 \mathrm{~cm}$ ), which is used as the equivalent of a measuring tape or ruler (Of course, the obvious problem with this is that the length of the first phalange of the fore-finger varies from person to person) and the finjal, which is the local name for the traditional coffee cup usually used to measure water when preparing aqueous mixtures of plant material as well as to administer the treatment. It is also worth noting that, for many treatments, clear distinctions are made between the dose given to children as opposed to adults.

On the mystical side, one is intrigued by the various chants and prayers recited when collecting many of the medicinal plants. In some cases, the patient is not even required to ingest, or for that matter have any apparent contact with, the plant believed to have healing properties. Another example is the significance of the numbers 3,5 and 7 , which may be viewed as the interface between the empirical and the mystical. There are often specifications for gathering leaves from 3, 5 or 7 different branches of a single plant, or, in the case of root parts, 3, 5 or 7 different plants. Those reporting this practice could not quite explain the reasons behind it. It would indeed be interesting to investigate how these numbers first came to be used and eventually evolved into 'standards'. It may be possible that such traditional collecting strategies originated partly in recognition of the different levels of concentration of the active constituent found in different plant parts or perhaps, as a basic traditional conservation concern.

Traditional wisdom vis à vis harmful traditional practices With increasing interest in this area, 'traditional knowledge' 'traditional practices' have almost exclusively become as- sociated with positive outcomes. If traditional health systems are to be strengthened as a whole, due attention should also be given to harmful practices. Cases in point, are traditional surgical procedures such as removal of tonsils and teeth, and the even graver practices of blood-letting and female circumcision, which are still widespread in all of the communities in this study.

\section{Conclusions}

\section{Building bridges within traditional knowledge systems}

What contribution that can be made by such basic community-based ethno-medical/ethno-botanical investigations? Over the last decade or so, research on traditional knowledge, particularly regarding the use of medicinal plants, has been fraught with debates regarding intellectual property and traditional resource rights. Arguably driven primarily by interests and forces external to indigenous communities, these are extremely complex and indeed urgent issues with which policy makers, and stakeholders from both the North and South, are actively grappling in various international fora. But this global focus has all too often diverted research attention away from the local context, i.e. away from the very local communities who depend on traditional health practices and thus from an improved understanding of the very basic nature, scope and current status of local traditional knowledge regarding the uses of medicinal plants. More importantly, preoccupation with such inescapable and pressing policy issues has meant that relatively little effort has been spared for grass roots research aimed at attaining a real understanding of the actual and potential roles traditional health knowledge and practices in meeting the arguably even more urgent health care needs of growing populations in resourceconstrained developing countries such as Ethiopia.

Hence, in the first instance, the hope is that this study and others like it can help to redirect some research attention to the community level. The study aims to demonstrate that, at least in the context or rural communities in the Northern Highlands in Ethiopia, traditional knowledge regarding the use of medicinal plants is far from being a corpus of wisdom or expertise that is restricted to a few elite professional traditional health practitioners - most of whom are men. Indeed, most of the traditional treatments used in the communities studied are managed, collected, prepared administered by lay community members - ordinary men and women -- at the household level.

This study has also been an attempt to peer behind the widely, and all too often mindlessly cited $80 \%$ figure, i.e. $80 \%$ of the developing world population, of Africans, of Ethiopians etc., who rely on traditional plant derived medicines for primary health care needs. The aim has been to shed some light on what 'relying on traditional health prac- 
tices and medicines' actually means. The evidence suggests that it does not necessarily mean that those $80 \%$ invariably consult professional traditional health practitioners. Indeed, it appears that there is considerable traditional health knowledge in the public domain. The fact that traditional health knowledge is so pervasive, and the use of local medicinal plants so widespread, has staggering public health implications which simply cannot be ignored by those concerned with development and the promotion of public health and natural resources management. Inevitably, questions emerge regarding whether this widespread cultural knowledge is challenged, limited or threatened in any way. Thus, future research and development efforts should aim to devise ways of addressing the challenges, limitations and threats identified with the ultimate goal of strengthening and improving traditional health knowledge and practices for the benefit of those who rely on them. The task at hand is indeed one of 'building bridges'. But before embarking on brave new constructs leading outwards and beyond the 'traditional' realm there may be a number of 'internal' bridges to be built, rebuilt or reinforced, to which this research hopes to draw attention.

Foremost are the mechanisms and channels for the transmission of traditional knowledge. Traditional knowledge, particularly oral doctrines, may be threatened because of continued demographic changes, and external 'modernisation forces' including urbanization, formal education, and ironically, even the expansion of modern medicine. What can be done about this? The answers may well be found among indigenous communities or they may come from innovative linkages with resources outside the realm of traditional knowledge systems. Basic studies, such as the present one, aimed at assisting communities in preserving their oral health traditions through systematic documentation of their knowledge and practices, can be viewed as a first step.

The second 'construction project' is one of bringing together different bodies of information and research on the traditional knowledge of communities in order to attain a better understanding of 'the whole'. This study has argued that, in the Ethiopian context, bridges between 'plants professionals and parchments' are needed, i.e. linkages between the knowledge and understanding acquired through past work which has focused on specific medicinal plants, professional health practitioners or the ancient herbal manuscripts.

Finally, there is the more ambitious endeavour of 'crosscultural viaducts', i.e., bridges between the traditional knowledge systems and practices of different cultural groups. Many related medicinal species are used in local cultures in distant countries and even in entirely different continents. It is interesting to note without looking too far, for example, that species related (albeit only at the genus level) to those used medicinally by local communities in Belize, including, Kalanchoe spp., Croton spp., Lippia spp. and Aloe spp. (Balick \& O'Brien 2004) also feature in the traditional pharmacopoeia of the local Ethiopian communities involved in the current study. Thus, exchanges among different cultural groups within a country, as well as among traditional communities in different parts of Africa or elsewhere in the world, can be viewed as a vital step towards building a 'global traditional knowledge community'-which is increasingly being recognized and valued as an indispensable complement of the global scientific community.

\section{Acknowledgements}

The author acknowledges with great gratitude the contributions of all those who made this study possible. First and foremost, special thanks go to the members of all five of the participating communities: Robit Bata, Yinesa-Sostu, Yigoma-Huletu, Wendata, Yiganda M. Zegie for sharing their valuable knowledge and time as well as for their tremendous generosity and hospitality. Also greatly appreciated are all those who provided invaluable field support: the Western Gojam Zonal Agriculture Development Bureau, including Ato Ghirma Mogess (Director), general staff and all the development agents responsible for each of the communities; as well as the B/Dar Fisheries Research \& Training Centre, particularly, Dereje Dejene and Martin DeGraff, PhD researchers from Wageningen University who generously assisted with transportation to Yigenda Mehal Zegie. The advice provided by Dr. David Turton (International Development Centre) and Dr. Gerard Bodeker (GIFTS of Health) as well as Dr Zemede Asfaw at the Department of Biology of the Addis Abeba University are also duly acknowledged. Special thanks to Mr. Luigi Guarino, Senior Scientist at the International Plant Genetic Resources Institute, for his valuable comments on the draft manuscript. Finally, the author is grateful to all those at the International Development Research Centre (IDRC), Canada, who made this research possible through the provision of funding support.

\section{Literature Cited}

Abate, G. B., T. Gebre Egziabher \& M. Tadesse. 1976. A study on the medicinal plants of Ethiopia, Unpublished. Science Faculty, Addis Abeba University.

Abebe, D. \& E. Hagos. 1991. Plants as a primary source of drugs in traditional health practices of Ethiopia. Pp. 101-113 in Plant Genetic Resources of Ethiopia. Edited by J.M.M. Engels J. G. Hawkes \& M. Worede. Cambridge University Press, Cambridge.

Abebe, D. \& A. Ayehu. 1993. Medicinal Plants and Enigmatic Health Practices in Northern Ethiopia. World Health Organization, Ethiopian Ministry of Health Project No. AF/ ETH/TRM/001RB and the United Nations Development Programme. 
Abebe, W. 1986. A survey of prescriptions used in traditional medicine in Gondar Region, Northwestern Ethiopia: General pharmaceutical practice. Journal of Ethnopharmacology 18:47-165.

Agro-Bio Ethiopia. 1996. Six-hundred Ethiopian plants have medicinal value. www.wam.umd.edu/ tes/agrobioeth.html

Akerele, O. 1987. The best of both worlds: bringing traditional medicine up to date. Social Science and Medicine 24:177-81.

Anokbonggo, W.W. 1992. The role of African traditional medicine in health care delivery alongside modern medicine. Botany 2000: East and Central Africa NAPRECA 5: 25-35.

Asfaw, Z. 1998. Conservation and production of traditional medicinal plants in home-gardens: the case of Ethiopia. Regional Workshop on Medicinal Plants and Traditional Medicine, Capetown, South Africa.

Ayehu, A. 1987. Metsihafe Ise-Hiywot. (A compendium of herbal letters compiled and translated into Amharic by a prominent traditional religious Debterra: Ahadu Ayehu), Addis Abeba University.

Balick, M.J. \& H. O‘Brien. 2004. Ethnobotanical and Floristic Research in Belize: Accomplishments, Challenges and Lessons Learned. Ethnobotany Research and Applications 2:77-88.

Berhane-Selassie, T. 1971. An Ethiopian Medical Text Book written by Gerazmach Gabrawald Aragahan, Daga Damot. Addis Abeba University, Institute of Ethiopian Studies. Addis Abeba.

Bishaw, M. 1988. Integrating Indigenous and Cosmopolitan Medicine in Ethiopia. Southern Illinois University, Carbondale, Illinois.

Bishaw, M. 1991a. Promoting Traditional Medicine in Ethiopia: A Brief Historical Review of Government Policy. Social Science and Medicine 33:193-200.

Bishaw, M. 1991b. The role and status of women in traditional health care services in Ethiopia. Gender Issues in Ethiopia November 1991:55-65.

CSA. 1998. The 1994 Population \& Housing Census of Ethiopia. Results at country level: Volume I Statistical Report The Federal Democratic Republic of Ethiopia. Central Statistical Authority (CSA) June, 1998

Cunningham, A.B. 1993. African Medicinal Plants: Setting priorities at the interface between conservation \& prima- ry health care. People and Plants Working Paper. March, 1993.

Desta, B. 1993. Ethiopian traditional herbal drugs. Part II: antimicrobial activity of 63 medicinal plants. Journal of Ethnopharmacology 39:129-39.

FAO. 1996. Ethiopia: Country Report to the FAO International Technical Conference on Plant Genetic Resources, Leipzig, Germany, 1996. Food and Agriculture Organization of the United Nations (FAO), Rome.

van der Geest. 1997. Is there a role for traditional medicine in basic health services in Africa? A plea for a community perspective. Tropical Medicine and International Health 2:903-911.

Grimes, B.F. 1996. Ethiopia. Ethnologue 13th Edition. Summer Institute of Linguistics. Dallas, Texas.

IBCR. 1999. Biodiversity Conservation and Sustainable Use of Medicinal Plants: Project Proposal. Addis Abeba, Institute of Biodiversity Conservation and Research (IBCR), Addis Abeba.

IDRC. 1998. Guidelines for Integrating Gender Analysis into Biodiversity Research. Sustainable Use of Biodiversity Programme Initiative. International Development Research Centre (IDRC) Canada.

Jansen, P.C.M. 1981. Spices, condiments and medicinal plants in Ethiopia, their taxonomy and agricultural significance. Centre for Agricultural Publishing and Documentation, Wageningen.

Kaba, M. 1993. Indigenous Medical Beliefs and Practices among the Oromo of Illubabor. College of Social Sciences. Addis Abeba University. Addis Abeba.

Kenaw, S. 1997. Spirit possession as a center of health education: a case study from central Ethiopia. Ethiopia in broader perspective. Pp. 428-439 in Proceedings of the XIIIth International Conference of Ethiopian Studies Shokado Book Sellers, Kyoto, Japan.

Kiros, F.G. 1993. The Subsistence Crisis in Africa: the case of Ethiopia. ICIPE Science Press, Nairobi.

Kitaw, Y. 1987. A study of three communities in Ethiopia: Special Issue on Self-care. The Ethiopian Journal of Health Development. 2:9-75.

Kloos, H. 1976. Preliminary studies of medicinal plants and plant products in markets of central Ethiopia. Ethnomedicine 4:63-102.

Kloos, H., A. Tekle, L. Yohannes, A. Yosef \& A. Lemma. 1978. Preliminary studies of traditional medicinal plants 
in nineteen markets in Ethiopia: use patterns and public health aspects. Ethiopian Medical Journal 16:33-43.

Low, G.L., J. Rogers, S.P. Brumley \& D. Ehrlich. 1985. Visual deficits and retino-toxicity caused by the naturally occurring anthelmintics, Embelia ribes and Hagenia abyssinica. Toxicology and Applied Pharmacology 81:220-230.

Marshall, N.T. 1998. Searching for a Cure: Conservation of Medicinal Wildlife Resources in East and Southern Africa. TRAFFIC International, Cambridge, UK.

MOH. 1985. Ministry of Health Primary Health Care Review. Ministry of Health, Addis Abeba.

Sindiga, I. 1995. African ethnomedicine and other medical systems. Pp. 16-29 in Traditional Medicine in Africa. Edited by N.C. Sindiga \& M.P. Kanunah. English Press Ltd., Nairobi.

Slikkerveer, L.J. 1990. Plural Medical Systems in the Horn of Africa - The Legacy of "Sheikh Hippocrates". Kegan Paul International, London.

Tadesse, M. \& S. Demissew. 1992. Medicinal Ethiopian plants: Inventory, identification and classification. Botany 2000: East and Central Africa NAPRECA Monograph 5:119.

Young, A. 1976. Internalizing and externalizing medical belief systems: an Ethiopian example. Social Science and Medicine 10:147-156.

Young, A. 1982. The Amhara Medical System. Pp. 21-41 in African Health and Healing Systems: Proceedings of Symposium. Edited by P.S. Yoder, Crossroads Press, University of California. Los Angeles. 
